\title{
Who Needs a Doctor Anymore? Risks and Promise of Mobile Health Apps
}

\author{
Pertti Huuskonen \\ Bsoniq Ltd \\ Nirvanrinteenkatu 1 \\ 33820 Tampere, Finland \\ bertil@bsoniq.com

\section{J onna Häkkilä} \\ University of Lapland \\ Laajakaista 3 \\ 96400 Rovaniemi, Finland \\ jonna.hakkila@ulapland.fi

\section{Keith Cheverst} \\ Lancaster University \\ LA1 4WA UK \\ Lancaster, UK \\ k.cheverst@lancaster.ac.uk
}

Permission to make digital or hard copies of part or all of this work for personal or classroom use is granted without fee provided that copies are not made or distributed for profit or commercial advantage and that copies bear this notice and the full citation on the first page. Copyrights for thirdparty components of this work must be honored. For all other uses, contact party componthor. the Owner/Author.

Copyright is held by the owner/author(s).

(15 Adjunct, August 24-27, 2015, Copenhagen, Denmark .

http://dx.doi.org/10.1145/2786567.2806675

\begin{abstract}
Personal health monitoring is a hot topic. With bracelets and other wearables, we keep track of our heart rate, exercising, sleep, and more. We are becoming our own doctors and coaches. Improving citizens' health brings the society significant savings, besides healthier citizens. Health data also has important value beyond healthcare, e.g. in insurance and advertising. However, risks on privacy, data management, information interpretation and incorrect health diagnosis and treatments exist. This panel discusses the promise and risks related to mobile health apps, highlighting both research and industrial aspects related to the current trends.
\end{abstract}

\section{Author Keywords}

Health; wellness; privacy; mobile apps; wearable technologies; mobile interaction; quantified self.

\section{ACM Classification Keywords}

H.5.m. Information interfaces and presentation (e.g., $\mathrm{HCl}$ ): Miscellaneous.

\section{I ntroduction}

Mobile technologies have become omnipresent in our everyday life. People are increasingly commonly equipped not only with mobile phones but also with different wearable technologies - bracelets measuring 
step count and sleep, heart rate monitors, or smart watches to provide easy-to-glance user interfaces (UIs). Many of these technologies are used to track our physical activity and performance data. With the rapidly grown mobile app market, the possibilities to provide applications that help people to become aware of their lifestyle and change their behavior towards a healthier life have exploded. However, the analysis on the popular smart phone wellness apps has shown that there remains significant possibilities to develop the UIS from simple data presentation towards conversational and guiding UIs [4]. Preceding the industrial application development happening now, $\mathrm{HCl}$ research has addressed mobile health and wellness technologies e.g. from the perspective of providing insights to the social competitive aspect [1], self-reflection [7] and design guidelines [3]. The most recent research trends are adding on e.g. understanding the quantified-selfers [6] and sports technique improvement [8].

\section{Risks and Promise}

The advance of ultra-cheap biometric sensors for consumer use promises even more physical measurement data in the coming years. ABI Research projects the wearable medical device sales will reach more than 100 million by 2016, with major growth ahead [9]. Society has major interest in preventive healthcare. Lifestyle changes that help to improve the citizens' health can bring tremendous savings in public spending. Personal health monitoring promises not only to bring citizens better health, but also more efficient health services, enabled by personally collected health data being shared to health professionals.

Smart phones and associated cloud services are the key platform for personal health monitoring. Apps and services for this purpose proliferate and risks inevitably arise. Misplaced sensitive data can be embarrassing, costly and dangerous. Data mining may uncover identifiable information from seemingly anonymous data. Personal health data has definite business value for the health industry, but also for secondary markets such as insurance and advertising.

Furthermore, it is not clear how much people can actually benefit from the increased amount of data (and in many ways represents an example of so-called 'Big Data'). It is unlikely that the average citizen can function as a data analyst. The analysis must be done by sufficiently easy-to-use software, but to what extent can we trust their automated diagnoses? Questions that arise include: suitable system architectures, security approaches, data ownership and appropriate interfaces to support scrutability of the sensed data and inferences made from this data $[2,5]$. How to extract maximal benefits from health data with minimal risks? Field experiments are underway - in your pockets.

\section{Panelists}

Alan Chamberlain is Senior Research Fellow at University of Nottingham, UK. He does research on ethnography, action research, participatory design, and user engagement, focusing especially on the in-the-wild aspects. His current research interests include e.g. user research on the quantified-self target group.

Jani Mäntyjärvi works as a Principal Scientist at VTT Finland's Technical Research Center, Finland. In addition, he is an entrepreneur in a sensor technologies health start-up, and Adjunct Associate Professor at University of Oulu, Finland. His expertise is in mobile sensor technologies and $\mathrm{HCl}$. 
Natasa Milic-Frayling is Principal Researcher at Microsoft Research Cambridge, UK. She has lead versatile research projects on mobile communication technologies and $\mathrm{HCl}$, including health and wellness. Her expertise includes social networks, sensors and algorithms, and mobile $\mathrm{HCl}$.

Stina Nylander is a researcher at SICS Swedish ICT, Sweden, focusing on $\mathrm{HCl}$ and user centric design. Her current research interests include persuasive technologies, behavior change, and $\mathrm{HCl}$ in sports.

Maritta Perälä-Heape is the leader of the Centre for Health and Technology, University of Oulu, Finland. She is currently leading national strategic research project Digital Health Revolution, which focuses on utilizing people's digital footprint for improving their health and lifestyle.

Henrik Sjöstrand is Chief Technology Officer at IBM. He works at IBM Public Sector CTO Team Europe and is based in Sweden. His focus area is mobility and mobile technologies, and he has, for example, developed applications for the management of diabetes.

\section{Acknowledgements}

This research has been supported by a grant from Tekes - the Finnish Funding Agency for Innovation as part of Digital Health Revolution programme.

\section{References}

1. Ahtinen, A., Huuskonen, P., Häkkilä, J. 2010. Let's All Get Up and Walk to the North Pole: Design and Evaluation of a Mobile Wellness Application. In Proc. NordiCHI 2010, 3-12. ACM.
2. Cheverst, K., Byun, H. E., Fitton, D., Sas, D., Kray, C., Villar, N. 2005. Exploring Issues of User Model Transparency and Proactive Behaviour in an Office Environment Control System. User Modeling and User-Adapted Interaction 15, 3-4 (Aug 2005), 235273.

3. Consolvo, S. Everitt, K., Smith, I., Landay, J.A. 2006. Design Requirements for Technologies that Encourage Physical Activity. In Proc. CHI'06. ACM.

4. Häkkilä, J., Colley, A., Inget, V., Alhonsuo, M., Rantakari, J. 2015. Exploring Digital Service Concepts for Healthy Lifestyles. In Proc. $\mathrm{HCl}$ International 2015, Springer.

5. Kay, J., Kummerfeld, B. 2013. Creating personalized systems that people can scrutinize and control: Drivers, principles and experience. ACM Trans. Interact. Intell. Syst. 2, 4, Article 24 (J an 2013), 42 pages

6. Kyoung Choe, E., Lee, N. B., Lee, B., Pratt, W., Kientz, J. A. 2014. Understanding quantifiedselfers' practices in collecting and exploring personal data. In Proc. CHI 2014, 1143-1152

7. Li, I., Dey, A. K., Forlizzi, J. 2011. Understanding my data, myself: supporting self-reflection with ubicomp technologies. In Proc. Ubicomp 2011, 405414

8. Nylander, S., Jacobsson, M., Tholander, J. 2014. Runright: real-time visual and audio feedback on running. In CHI'14 Extended Abstracts, 583-586.

9. www.abiresearch.com/market-

research/product/1005339- wireless-health-andfitness/ (Last accessed: July 15, 2015) 